\title{
Primary Peritoneal Low Grade Serous Adenocarcinoma
}

National Cancer Institute

\section{Source}

National Cancer Institute. Primary Peritoneal Low Grade Serous Adenocarcinoma. NCI

Thesaurus. Code C126354.

A serous adenocarcinoma that arises from the lining of the peritoneum. It is characterized by low grade histopathologic features. 